\title{
The development of self-reinforcing running in satiated rats*
}

\author{
LUCI PAUL and FRANK CALABRESE \\ Temple Unn'ersity, Philadelphia, Pennsyliania 19122
}

\begin{abstract}
Fast. "playful" running was obtained in rats never given reward for running in an alley. The maintenance of such running was not dependent on hunger, thirst, or an "exercise" drive produced by confinement in small home cages. However, hunger facilitated the development of "playful" nonrewarded running in rats which initially did not run when food-satiated. "Playful" running was not seen in hungry, rewarded rats or in hungry, nonrewarded rats fed immediately after their daily running sessions. Probably incentive, but not drive, prevents the occurrence of self-reinforcing running.
\end{abstract}

Thousands of rats have eventually failed to run in an alley when reward for running was discontinued. Nevertheless, a few studies have reported well-maintained, unrewarded running. Sometimes, unrewarded running has been slow in comparison to food-rewarded running (Logan, 1960; Marx, 1967; Weinstock, 1958), but in other instances it has been as fast as food-rewarded running (Paul, 1969) or even faster (Clark \& Miller, 1966). Rats may have considerable motivation for running, per se, and we do not yet understand its nature.

Two views have been taken. First, unrewarded running has been attributed to general activity produced by hunger and/or by an activity drive (Clark \& Miller, 1966; Logan, 1960). Previous investigations certainly can support this view, because they have all used hungry rats. Second, Logan suggested, from a comparison of two experiments, that rats living in smaller cages ran faster than rats living in larger cages. If the view of Clark and Miller and of Logan were correct, it should not be possible to find fast (highly motivated) running among food-satiated rats or among rats living in very large home cages.

However, Paul (1969) observed that unrewarded running was "playful" and assumed it to be self-reinforcing, the motivation and reinforcement lying in the making of the response (Harlow, 1953; Koch, 1956). If this view were correct, neither food satiation nor the use of very large home cages should prevent the development of fast, unrewarded running.

It is important to ascertain which view is correct. Several recent reviewers have questioned the generality of laws governing extrinsically rewarded responses (Bolles, 1970; Seligman, 1970), and it is quite possible that the laws governing self-reinforcing responses are not the same as those governing extrinsically rewarded responses. If alley running by rats can be shown to be self-reinforcing, the running response would provide, for future investigations, a particularly simple and useful

*This investigation was supported by Public Health Service Research Grant MH 11984-01 and a Temple University Faculty Grant-in-Aid to the senior author. The authors thank Eileen B. Karsh for helpful comments on an earlier version of this paper. means of comparing extrinsically rewarded running with self-reinforcing running.

\section{EXPERIMENT I}

To determine whether hunger is necessary to obtain fast, unrewarded running, we compared the performance of (a) rats maintained on ad lib food and never rewarded for running, (b) hungry rats given food reward for each run, and (c) hungry rats not rewarded for running.

\section{Method}

\section{Subjects}

Thirty-five male Sprague-Dawley rats, weighing $300-350 \mathrm{~g}$ (approximately 85 days of age) at the start of the experiment were housed in $8 \times 9 \frac{1 / 2}{2} \times 7$ in. individual cages.

\section{Apparatus}

Ss ran in a $48 \times 4 \times 4$ in. straight alley of unpainted wood with a clear Plexiglas top. At each end of the alley was a $12 \times 12$ $x 12$ in. wood endbox with a clear Plexiglas top. A dipper delivered $1 \mathrm{~g}$ of liquid food ( 2 parts powdered chow to 5 parts water) through a hole at the rear of each endbox.

To record running times, photocells were placed 1 in. in front of each endbox, at a height of $1 \mathrm{in}$. The photocells, with appropriate circuitry, were connected to an Esterline-Angus recorder.

\section{Procedure}

Ss were assigned randomly to three groups. Group H-R (hungry-rewarded in the alley, $\mathrm{N}=10$ ) was given food reward after each one-way shuttle in the alley and fed for $1 \mathrm{~h}$ daily, immediately after each experimental session. Group S-NR (satiated-nonrewarded in the alley, $\mathrm{N}=13$ ) had food ad lib throughout the experiment. These rats were never rewarded in the alley. Group H-NR (hungry-nonrewarded in the alley, $N=12$ ) was never rewarded in the alley. They were fed $1 \mathrm{~h}$ daily, immediately after each experimental session, and thus served as a control for the possibility that running in Group S-NR was reinforced by removal from the alley.

All $S$ s had ad lib food for 7 days. Groups $H-R$ and $H-N R$ were then maintained on a 23-h food-deprivation schedule for the remainder of the experiment. All Ss had free access to water throughout the experiment.

Habituation training. For 2 weeks, all Ss were handled each day for $2-3 \mathrm{~min}$. Next, Ss were placed in a carrying rack of 


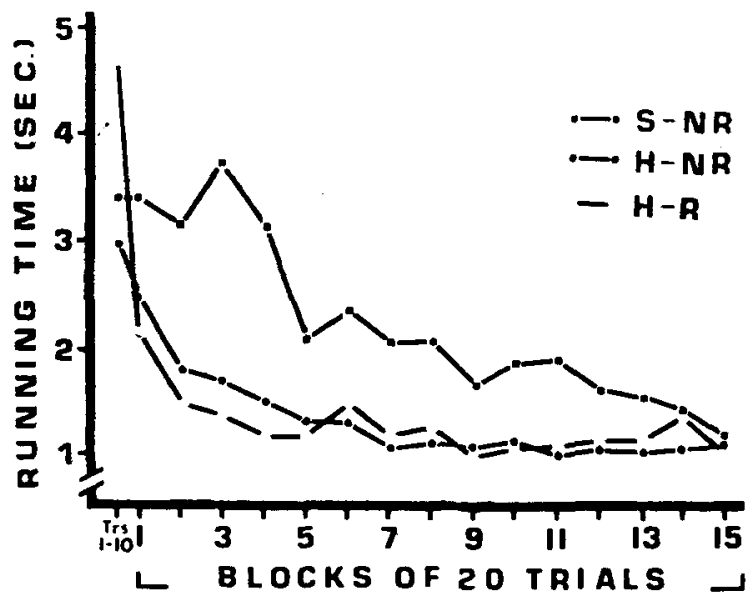
trials.

Fig. 1. Group means of median running times on blocks of

individual cages. $12 \times 9 \times 7$ in., with water available for all $\mathrm{Ss}$ and food available for Group S-NR. Ss were wheeled into the experimental room. then placed in a closed endbox for $15 \mathrm{~min}$ on each of 4 days. Ss in Group H-R received a dish of wet mash in the endbox; Ss in Groups H-NR and S-NR did not.

Alley training. On each day, Ss were placed in the right-hand endbox and allowed to shuttle back and forth freely between the two endboxes for a specified number of trials. A trial was defined as a one-way shuttle from the photocell at one end of the alley to the photocell at the other end of the alley. Ss ran 2 trials on the first day of alley training, 4,6 , and 8 triais, respectively. on the next 3 days, and 10 trials a day thereafter, for a total of 310 trials. After completing each trial, $S_{s}$ in Group H-R received a dipper of wet mash. The food dipper and floor of the endbox around the dipper were washed before trials of Groups H-NR and S-NR, in order to prevent secondary reinforcement from food odors.

A nonresponse criterion of 5 min without completing a trial on 3 successive davs was used to identify nonresponders. To investigate further the role of hunger in the development of unrewarded running, two of the five $S s$ in Group S-NR that reached this criterion were placed on food deprivation for 1 week, then returned to ad lib food. Daily running sessions for these Ss were continued.

Two performance measures were obtained: running time (between the last break of the photocell at one end of the alley to the first break of the photocell at the opposite end of the alley) and total time (between the first break of the photocell upon entering an endbox at one end of the alley to the first break of the photocell upon entering the endbox at the opposite end of the alley).

\section{Results}

Seven Ss reached the nonresponse criterion, one from Group H-R, one from Group H-NR, and five from Group S-NR, but the groups did not differ significantly in the number of dropouts $\left(\chi^{2}=2.31 . \mathrm{df}=2, \mathrm{p}>.30\right)$. The data from these Ss were not included in the analyses of running and total times, leaving 9 Ss in Group H-R. $11 \mathrm{Ss}$ in Group H-NR. and 8 Ss in Group S-NR.

Figure 1 shows the mean of median running times for each group on the first 10 trials, and, thereafter. the group means of medians on blocks of 20 trials. The two hungry groups (H-R and H-NR) were much alike in running time and were faster than the food-satiated group until the last blocks of trials. The two hungry groups reached an asymptotic level of running after about 190 trials, whereas the running times of Group S-NR continued to decrease over all 310 trials. Considering all 310 trials, the three groups differed in running times $(F=9.30, d f=2,25, p<.01)$, and there was an interaction of groups with trials $(F=2.86$, df $=$ $60,750, \mathrm{p}<.01)$. However, on the last 40 trials, the three groups did not differ $(F<1)$.

Figure 2 shows the mean of median total times for Groups S-NR and H-NR on the first 10 trials and, thereafter, on blocks of 20 trials. Total-time scores for Group H-R are not given, because they spent several seconds eating on each trial.

Over all 310 trials, Group S-NR took more time per trial than did Group H.NR ( $F=16.40$, df $=1,17$, $\mathrm{p}<.01$ ), and there was no interaction between groups and trials $(F=1.32, \mathrm{df}=30,510, \mathrm{p}>.05)$. Group S-NR also spent more time per trial on the terminal trials (last 40) of the experiment than did Group H-NR ( $t=6.20$, $\mathrm{df}=15, \mathrm{p}<.01)$.

A most salient feature of behavior in Group S-NR, but not of behavior in Groups H-R and H-NR, was "playfulness." Ss in Group S-NR were extremely active in the endboxes, sniffing the floor and sides, and hopping in circles or back and forth. They galloped, rather than ran, down the alley. On many trials, the animals braked sharply at the end of a run, paused, then lunged past the photocell beam, which produced an audible click of the relays. Many animals started a run by a hop into or toward the alley from within the endbox, then jumped back and forth in a half circle within the endbox, finally bounding into the alley for a complete run. A number of rats spontaneously developed aggressive games. When about to be picked up in the home cage or in the endbox, they ran from E's hand, then returned to bite the hand, using a very fast movement which never broke the skin.

The two Ss in Group S-NR that were food deprived for 1 week after reaching the nonresponse criterion did

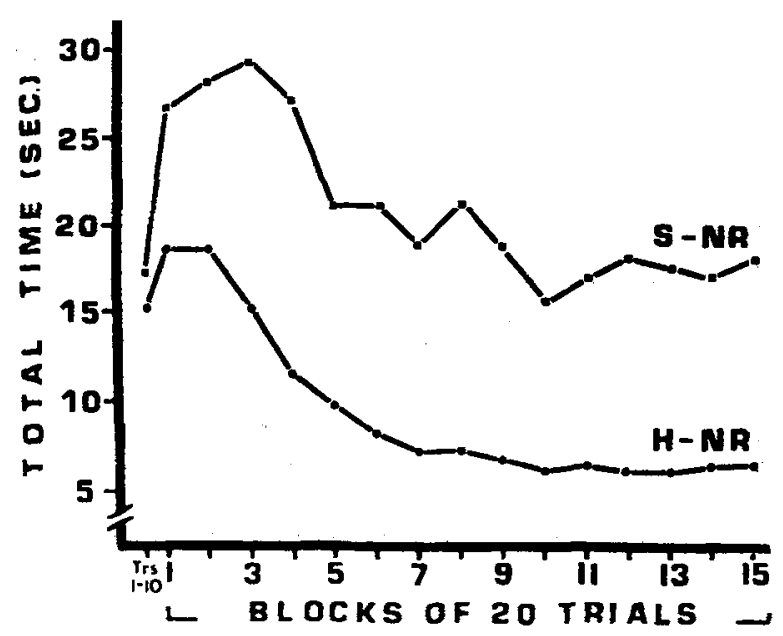

Fig. 2. Group means of median total times on blocks of trials. 
run while food deprived, and they continued to run after being returned to ad lib food. Both eventually developed some "playful" behavior.

\section{EXPERIMENT II}

This experiment determined whether fast, nonrewarded running reflects an "exercise" drive produced by confinement in small home cages. If so, permitting rats to live in large home cages, where they can run, jump, and climb should prevent the development of fast, nonrewarded running.

In Experiment I, the two rats in Group S-NR which were placed on a food-deprivation schedule after they had reached the nonresponse criterion did continue to run after being returned to ad lib food. These data suggest that hunger may facilitate the development of self-reinforcing running. Therefore, all rats in this experiment that reached the nonresponse criterion were food deprived for 1 week and then returned to ad lib food, with daily running sessions continued.

\section{Method}

\section{Subjects}

Twenty male Sprague-Dawley rats, weighing $340-370 \mathrm{~g}$ (approximately 95 days of age) at the biginning of the experiment, served as Ss.

\section{Apparatus}

Ss in Group Sm lived in small, individual, wire-mesh cages, $8 \mathrm{x}$ $91 / 2 \times 7 \mathrm{in}$., and those in Group Lg lived in large, individual, wire-mesh cages, $24 \times 17 \times 14$ in., with a metal floor covered with wood shavings. These cages permitted some running, climbing the sides, and jumping onto a food hopper.

The straight alley was the same as that used in Experiment I.

\section{Procedure}

Ss were assigned randomly to Groups $\mathrm{Sm}$ and $\mathrm{Lg}$.

Both groups were placed in the appropriate home cages upon receipt from the supplier. After 7 days in the home cages, Ss

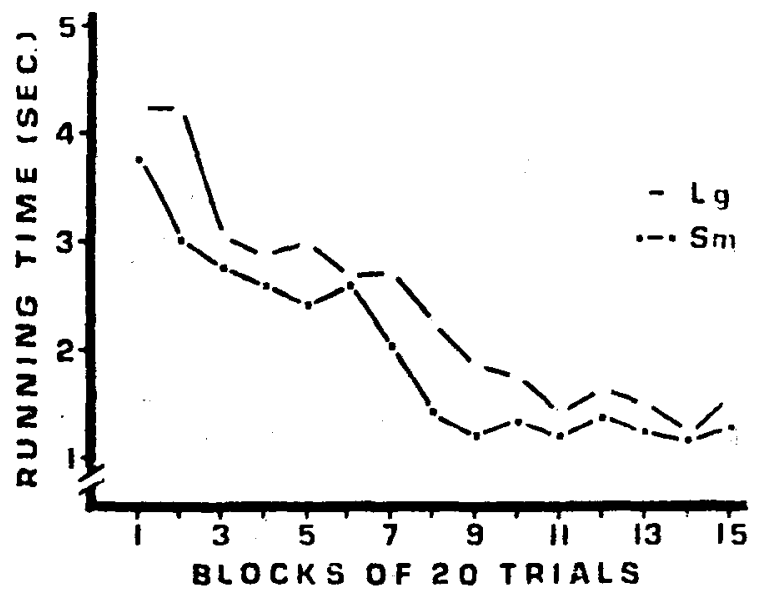

Fig. 3. Group means of median running times on blocks of 20 trials.

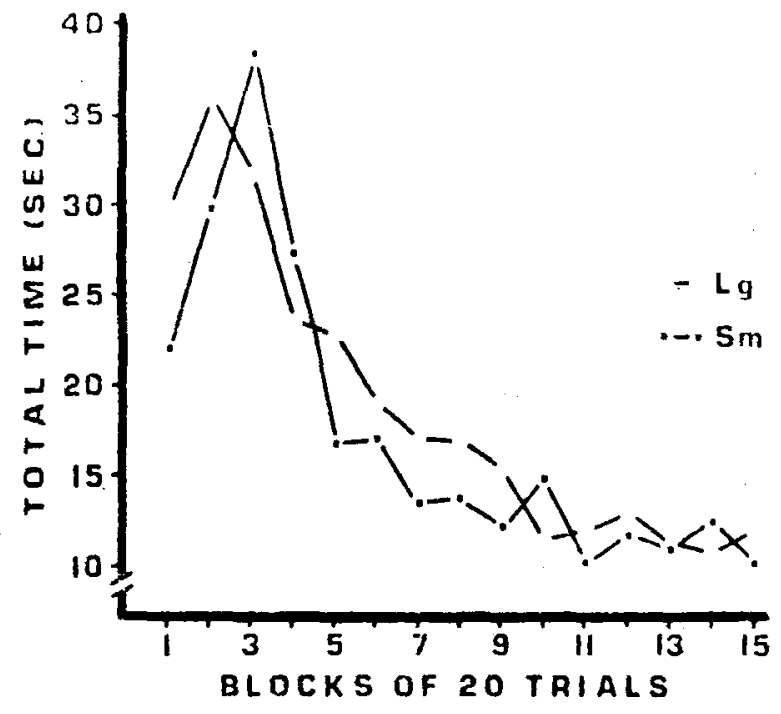

Fig. 4. Group means of median total times on blocks of 20 trials.

were handled for $1-2 \mathrm{~min}$ on each of 8 consecutive days. Over the next 5 days, Ss were placed in individual cages, $12 \times 9 \times$ $7 \mathrm{in}$, and were wheeled into the experimental room for $10 \mathrm{~min}$ each day. To accustom $S s$ to the noise of the apparatus, E operated relays occasionally during these $10 \mathrm{~min}$. Throughout the experiment, Ss had food and water ad lib in carrying and home cages.

A total of 300 trials in the alley was given. The procedures used in alley training were the same as those used in Experiment I for nonrewarded Ss, with one exception. Ss that failed to complete a trial within 5 min on 3 consecutive days, after having run at least 10 trials, were placed on a food-deprivation schedule for 1 week, then returned to ad lib food. Such Ss were run daily in the alley for the duration of the experiment.

\section{Results}

Two Ss (both in Group Sm) died after having completed 120 and 240 trials, respectively. Prior to death, both Ss ran at speeds comparable to those of the other Ss (median running times of 1.25 and $1.33 \mathrm{sec}$, respectively). Three Ss in Group Sm and two Ss in Group $\mathrm{Lg}$ reached the nonresponse criterion. Four of these Ss (two from Group Lg and two from Group Sm) ran when food deprived and continued to run when returned to ad lib food. Data from these Ss are not included, leaving five Ss in Group Sm and eight Ss in Group Lg.

Figure 3 shows the mean of median running times for the two groups on blocks of 20 trials. Figure 4 shows the mean of median total times in both groups on blocks of 20 trials. The performance of both groups was similar. Over all 300 trials, the two groups did not differ in running time $(\mathrm{F}=1.29, \mathrm{df}=1,11, \mathrm{p}>.05)$ or in total time $(F<1)$. There was no interaction between groups and trials for running time $(\mathrm{F}<1)$ or for total times ( $\mathrm{F}$ $=1.07, \mathrm{df}=29,319, \mathrm{p}>.05$ ).

The "playfulness" and peculiarities of running which characterized Group S-NR in Experiment I were 
observed in the Ss in this experiment. Indeed, these two groups replicated closely the data of Group S-NR in Experiment I, except that $S s$ in the present experiment reached an asymptotic running time in fewer trials.

\section{DISCUSSION}

Fast, unrewarded running was obtained in a large percentage of rats that were neither food nor water deprived. In the two experiments, 23/33 (70\%) food-satiated rats ran 300 or more trials without reward, and they eventually reached speeds comparable to those of hungry, unrewarded rats. Contrary to previous suggestions (Clark \& Miller, 1966; Logan, 1960), then, such running need not reflect activity produced by hunger.

Similarly, fast, unrewarded running did not appear to reflect an "exercise" drive due to confinement in small home cages. Eight of the 10 food-satiated rats living in very large home cages did develop fast running, and the other two rats developed fast running after being food deprived for a week. Although our conclusion here is based on a small number of animals, there was no indication in Experiment II that Group Lg differed from Group Sm. Such should not have been the case if confinement in small home cages were critical to the development of unrewarded running. Although both Logan (1960) and Clark and Miller (1966) suggested that an "exercise" drive was important to unrewarded running, only Logan (1960, p. 43) compared speeds of animals living in home cages of different sizes. However, Logan's comparison was made across experiments, and his unrewarded rats did not show high speeds (close to those of rewarded rats), regardless of the degree of confinement. In addition, our large cages were clearly much larger, and therefore permitted much more exercise, than those used by Logan, who reported that his small cages severely restricted the movement of the animals and were one-half the size of his larger cages. Thus, Logan's larger cages were probably roughly comparable to our small cages. Finally, our data are in line with Lore's (1968) conclusion that severity of restriction is not related to the amount of activity.

Finally, we do not think that running in the food-satiated groups was reinforced by stimuli associated with removal from the alley. In Experiment I. Group H-NR was fed inmediately after removal from the alley, but these animals did not develop playful running. It is, therefore, unlikely that reinforcement associated with removal from the alley would account for the different behaviors obtained in Groups S-NR and H.NR.

Considering its playful nature, fast, unrewarded running can, apparently, be self-reinforcing. This interpretation is supported by the speeds eventually attained by the food-satiated rats. indicative of high motivation. Their high total-time scores reflected the time taken up by the playful responses. Nevertheless. it is important to note that self-reinforcing running developed quite slowly in comparison to food-rewarded running and that, although the difference was not statistically reliable, more food-satiated rats failed to run than did food-rewarded rats. However, when one considers the failure rates of other self-reinforcing responses, e.g., sexual behavior in male rats, the drop-out rate here does not seem excessive. Indeed, given the very slow running of food-satiated rats on the early trials, it is surprising that any of these rats developed fast running. That a large majority did indicates the potency of reinforcement from running.

Some of the reinforcement for running may be feedback from use of muscles used in running. Certainly, the playful responses observed in food-satiated rats would maximize the amount and type of muscular feedback. Furthermore, in other unrewarded situations, rats (Clark \& Miller, 1966) and deer mice (Kavanau, 1968) have chosen more difficult tasks requiring more effort and muscular coordination. If such muscular feedback were the reinforcement, the animal would have to produce these responses before being maximally reinforced. Given the tendency of rats to move slowly on initial trials in a runway, it is possible to understand why fast. playful running develops so slowly in comparison with food-rewarded running and why a number of food-satiated rats failed to continue to run.

Accordingly, any condition, such as hunger, which would increase the activity of the animal should facilitate the development of self-reinforcing running by increasing the probability of reinforcement from muscular feedback. Indeed, six of the seven rats that were food deprived for a week after failing to run while food satiated did run when food deprived, and they continued to run (and showed playful behavior) when returned to adlib food. Furthermore, in the two previous investigations (Clark \& Miller, 1966; Paul. 1969 ) in which nonrewarded rats ran at least as fast as food-rewarded rats, the rats were hungry and no rats failed to run.

If hunger does facilitate the development of self-reinforcing running by increasing the probability of reinforcement from muscular feedback, hunger should not be necessary to the maintenance of unrewarded running. This was the case for our six rats, which continued to run when returned to ad lib food. Similar data have been obtained for other self-reinforcing responses. Shock can induce noncopulating rats to copulate (Caggiula \& Eibergen, 1969), but it is not necessary for continued copulatory behavior (Crowley. Popolow, \& Ward. 1972). Hunger can induce rats to kill mice, but such rats continue to kill when returned to ad lib food (Paul. Miley. \& Baenninger, 1971). Perhaps in all these instances, the role of the potentiating or arousing condition is only in eliciting the response and thereby ensuring reinforcement from the making of the response.

Our conclusion about the role of hunger, or other 
arousing conditions, in the development of self-reinforcing responses is contrary to the view that the presence of strong homeostatic drives prevents the occurrence of self-reinforcing responses (Harlow, 1953; Koch, 1956). Our data suggest that an external incentive, rather than drive, prevents the development of self-reinforcing running. Food-rewarded rats have not shown the behaviors (playfulness, choice of more effortful response) characteristic of self-reinforcing running (Experiment I; Clark \& Miller, 1966: Paul, 1969). Furthermore, whereas hungry unrewarded rats fed $1 \mathrm{~h}$ after daily runs have developed these behaviors (Clark \& Miller, 1966: Paul, 1969), the hungry, unrewarded rats in Experment $I$, which were fed immediately after daily runs, did not do so. A 1-h delay of food prevents the feeding from providing incentive motivation for running (Finger, Reid, \& Weasner, 1957).

In summary, neither hunger nor an exercise drive are necessary to the development of playful, unrewarded running. However, some arousing conditions, such as hunger, may aid its development, whereas external incentives appear to prevent its development.

\section{REFERENCES}

Bolles, R. C. Species-specific defense reactions and avoidance learning. Psychological Review, 1970, 77, 32-48.

Caggiula, A. R., \& Eibergen, R. Copulation of virgin male rats evoked by painful peripheral stimulation. Journal of Comparative \& Physiological Psychology, 1969, 69, 414-419.

Clark, J. W., \& Miller, S. B. The development of rapid running in $\mathrm{T}$-mazes in the absence of obvious rewards. Psychonomic Science, $1966,4,127-128$.
Crowley. W. R.. Poplow, H. B.. \& Ward, O. B. From dud to stud: Elicitation of copulatory behavior in noncopulator male rats by conditioned arousal. Paper presented at meeting of the Eastern Psychological Association, Boston. 1972.

Finger, F. W., Reid, L. S., \& Weasner, M. H. The effect of reinforcement upon activity during cyclic food deprivation. Journal of Comparative \& Physiological Psychology, 1957, 50, 495-498.

Harlow, H. F. Mice, monkeys, men, and motives. Psychological Review. 1953,60, 23-32.

Kavanau, J. L. Behavior of captive white-footed mice. Science. 1967. 155, 1623-1639.

Koch, S. Behavior as "intrinsically" regulated: Work notes towards a pre-theory of phenomena called "motivational." Nebraska Symposium on Motivation, 1956, 4, 42-86.

Logan. F. A. Incentive. New Haven: Yale University, 1960.

Lore, R. K. Activity-drive hypothesis: Effects of activity restriction. Psychological Bulletin, 1968, 70, 566-574.

Marx, M. H. Resistance to extinction as a function of delay of reinforcement and the opportunity to retrace in the runway. Psychonomic Science, 1967, 8, 287-288.

Paul, L. High performance obtained with no reward. Psychonomic Science, 1969, 14, 224-226.

Paul, L., Miley, W. M., \& Beanninger, R. Mouse killing by rats: Roles of hunger and thirst in its initiation and maintenance. Journal of Comparative \& Physiological Psychology, 1971, 76, 242-249.

Seligman, M. E. P. On the generality of the laws of learning. Psychological Review, 1970, 77, 406-418.

Weinstock, S. Acquisition and extinction of a partially reinforced running response at a 24 -hour intertrial interval. Journal of Experimental Psychology. 1958, 56, 151-158.

(Received for publication March 25, 1973; revision received June 23,1973 .) 